\title{
Analysis of Risk Perceptions and Related Factors Concerning COVID-19 Epidemic in Chongqing, China
}

\author{
Shan $\mathrm{He}^{1}$ - Siyu Chen ${ }^{2}$. Lingna Kong ${ }^{1}$ - Weiwei Liu ${ }^{3,4,5}$
}

Published online: 26 June 2020

(c) Springer Science+Business Media, LLC, part of Springer Nature 2020

\begin{abstract}
Objective To assess perceptions of risk and related factors concerning COVID-19 epidemic among residents in Chongqing city, China.

Methods With convenience sampling, a web questionnaire survey was conducted among 476 residents living in Chongqing on February 13rd to 14th in 2020, when citizens just started to get back to work.

Results Residents' estimated perceived risks were $(4.63 \pm 0.57),(4.19 \pm 0.76),(3.23 \pm 0.91)$ and $(2.29 \pm 0.96)$ for the infectivity, pathogenicity, lethality and self-rated infection possibility of COVID-19, respectively. Females (OR $=4.234)$, people with income $\geq 2000$ yuan (2000-4999 yuan: $O R=5.052,5000-9999$ yuan: $O R=4.301, \geq 10,000$ yuan: $O R=23.459)$, the married status $(\mathrm{OR}=1.811)$, the divorced status, widows or widowers $(\mathrm{OR}=3.038)$, people living with families including children $(\mathrm{OR}=5.085)$ or chronic patients $(\mathrm{OR}=2.423)$ had a higher perceived risk level, as well as people who used free media websites $(\mathrm{OR}=1.756)$, community workers $(\mathrm{OR}=4.064)$ or community information platforms $(\mathrm{OR}=2.235)$ as main media information sources. The perceived risk increased by $4.9 \%$ for every one-year increase of age. People who used WeChat contacts $(\mathrm{OR}=0.196)$ as the main media information source, reported a lower perceived risk.

Conclusion Residents reported a high level of risk perception towards COVID-19 in Chongqing and it was impacted by the population demographic characteristics. Media information sources, including community information platforms and community workers may cause the increase of public risk perceptions.
\end{abstract}

Keywords COVID-19 $\cdot$ Risk perception $\cdot$ Media information $\cdot$ Community $\cdot$ Residents

\section{Introduction}

Continuous and relentless attacks from emerging and reemerging pathogens create global challenges for public health [1]. In December 2019, some cases of severe

Weiwei Liu

lww102551@cqmu.edu.cn

1 School of Nursing, Chongqing Medical University, Chongqing 400016, China

2 Department of Epidemiology and Biostatistics, Southwest School of Medicine and First Affiliated Hospital, Army Medical University, Chongqing 400038, China

3 School of Public Health and Management, Chongqing Medical University, Chongqing 400016, China

4 Research Center for Medicine and Social Development, Chongqing 400016, China

5 Innovation Center for Social Risk Governance in Health, Chongqing 400016, China pneumonia of unknown cause linked to a seafood wholesale market occurred in Wuhan, Hubei Province, China [2]. This emerging infectious disease presented with fever, dry cough, fatigue, dyspnea, diarrhea even severe symptoms was later named coronavirus disease (COVID-19) by the World Health Organization (WHO).

Till February, 2020, the basic reproductive number $\mathrm{R}_{0}$ of COVID-19 was 2.2 in China, and its fatality rate (2.9\%) was lower than SARS (10\%) and MERS $(37 \%)[3,4]$. The rapidly increasing number of cases graved public's concerns about the future trajectory of the outbreak, especially with the approaching of Chinese Lunar New Year, an estimated 3 billion travels would be made during the Spring Festival vacation this year, which increased the risk of transmission from person to person [5]. Chinese health authorities and services acted immediately to characterize and control the disease. Strategies for the control and prevention of COVID19 included travel restriction, epidemic surveillance, quarantining source of infection and lockdown of communities. 
On January 21 st, 2020, the National Health Commission of the People's Republic of China confirmed that Chongqing had the first imported case from Wuhan [6]. Chongqing is one of the four province-level municipalities under the direct control of the state council. Chongqing has a residential population of over 31.24 million and an outflow population of over 11.78 million [7]. Its location is adjacent to Hubei province. The big population and migration during the Spring Festival put Chongqing at a greater risk facing the surveillance and control of COVID-19.

Chongqing initiated level I response to major public health emergencies on January 24th. The local government of Chongqing mobilized urban and rural communities to execute community-based control and prevention measures [8]. The precise and scientific community gridded management underlined epidemic monitoring, health campaign and health care for the vulnerable population including the elderly, people with underlying diseases, children and pregnant women. Community workers were advised to deliver public health education through WeChat groups and subscriptions, QQ groups and smart community platforms (WeChat and QQ are both instant messaging apps widely used in China). Residents were advised to stay at home, wear a mask outside, practice physical distancing, use cough etiquette, wash hands frequently, and report to community health service center when they were presented with suspected symptoms.

Previous studies have linked risk perceptions with individual behaviors. Risk perceptions examine the judgments that people use to characterize and evaluate hazardous activities [9]. Monitoring people's risk perceptions is part of emergency management in major public health emergencies. During the disease control and prevention, public risk perceptions are widely accompanied with the attitudes, emotional response and prevention behaviors, which have an impact on the evolution of emergencies [10]. The study of public risk perceptions towards COVID-19 may help to understand public's attitudes towards the emerging disease and to predict their behaviors.

The goal of this article is to measure what are the risk perceptions towards COVID-19 among Chinese residents in Chongqing, and to explore what factors may influence their perceived risk.

\section{Methods}

\section{Sample}

The survey was conducted in Chongqing, using a convenience sampling method. Inclusion criteria were: (1) Chinese residents who stayed in China during the past 6 months; (2) citizens living in Chongqing during the 2020 Spring Festival vacation; (3) use of smart phones.

\section{Measure}

The questionnaire was developed based on the concept of public risk perceptions and the epidemiological characteristics of COVID-19, by the first and correspondent authors, then piloted among co-authors to ensure its readability and content validity $[9,11]$. Domain 1 was citizens' demographics including gender, age, educational level and place of residence, et al. Participants were asked whether they lived with family members including the elderly, chronic disease patients, the pregnant, the puerperant and children.

In domain 2, we asked participants to choose the main channels to acquire information about COVID-19 from January 23rd to February 9th (the Spring Festival vacation). Options included new media, traditional media, community information platforms and community workers. Options were showed randomly in the online questionnaire. Participants were allowed to choose five items at most. This part aimed to explore the most commonly used information source by citizens during the Spring Festival vacation.

Domain 3 had four questions in 5-point Likert-type scale. Participants were asked to (1) estimate the risk of infectivity, pathogenicity and lethality of COVID-19 from 1, 'very low', to 5, 'very high', with 3 being 'moderate'; (2) rate their likelihood of being infected with COVID-19 from 1, 'extremely unlikely', to 5 , 'extremely likely', with 3 being 'neither unlikely nor likely'. To help participants to understand the means of these scientific terms, annotations were added below the questions: 'Infectivity differs across different infectious diseases. Infectivity is a pathogen's capacity to spread from one host to another.' 'Pathogenicity is the potential disease-causing capacity of pathogens. Pathogenicity is related to virulence.' 'Lethality is how capable of COVID19 is of causing death. We usually count dead cases among the patients.'

\section{Survey}

Online anonymous questionnaire survey was used in the study. The questionnaire was established using an online survey platform (Wen Juan Xing, wjx.cn) developed by Changsha Ran Xing technology company, then the questionnaire was forwarded and disseminated through WeChat and QQ from February13rd to 14th 2020. Each respondent was limited to reply only once and allowed to submit after all items were filled. The inclusion criteria, purpose of the study and information confidentiality were illustrated at the beginning, to obtain respondent's informed consent. After the questionnaire was filled and submitted, the page automatically skipped to a thank-you letter with recommendation of 
authoritative information resources: WeChat subscriptions 'Health China' managed by the National Health Commission of the People's Republic of China, 'Latest News of the Chinese Center for Disease Control and Prevention (CDC)' managed by the Chinese CDC and some educational reading materials. Ethical approval was obtained from the Ethics Committee of Chongqing Medical University.

\section{Statistical Analysis}

Statistical software package IBM SPSS Statistics 23.0 (IBM Corp., Armonk, New York, USA) was used for data input and analysis. Descriptive statistics like frequencies, means and standard deviations (SD) were used to describe the data. Chi-square test was used to examine the differences across categorical variables. Binary logistic regression analysis was used to explore the effect of demographics and information sources on risk perceptions. $P$ value of $<0.05$ was considered as statistically significant.

\section{Results}

A total of 479 questionnaire were collected and exported to an excel file. Then all data were checked by the place of residence to ensure that all samples met the inclusion criteria. Three were excluded because these respondents did not stay in China during the Spring Festival vacation. A total of 476 questionnaires were input to the database and used for data analysis.

\section{Demographics}

Of the 476 respondents, 465 resided in Chongqing during the last 6 months, and 11 resided in other cities and stayed in Chongqing during the Spring Festival. Participants were mostly women (the ratio of male/female was about 1:2). Participants' age was between 19 and 72 years of age. The median age was 34-year-old. The sample was highly educated. More than $80 \%$ had college degree or higher. The majority of the sample lived in the urban area of Chongqing (Table 1). The percentage of family members living with participants included the elderly $(274,57.56 \%)$, chronic disease patients $(210,44.12 \%)$, children $(157,32.98 \%)$, the pregnant $(16,3.36 \%)$, and the puerperant $(6,1.26 \%)$.

\section{Media Sources Used by the Residents}

Of all respondents, $56.93 \%$ used WeChat contacts (including friends and groups), and $51.26 \%$ used television to acquire information about COVID-19. WeChat contacts ranked the first in the new media and television ranked the first in the traditional media among the most commonly used media
Table 1 Demographic characteristics of respondents $(N=476)$

\begin{tabular}{|c|c|c|}
\hline & $n$ & $\%$ \\
\hline \multicolumn{3}{|l|}{ Gender } \\
\hline Male & 158 & 33.19 \\
\hline Female & 318 & 66.81 \\
\hline \multicolumn{3}{|l|}{ Age, year } \\
\hline$<30$ & 160 & 33.61 \\
\hline $30-$ & 158 & 33.19 \\
\hline $40-$ & 69 & 14.50 \\
\hline $50-59$ & 61 & 12.82 \\
\hline$\geq 60$ & 28 & 5.88 \\
\hline \multicolumn{3}{|l|}{ Educational level } \\
\hline Primary school or junior high school & 13 & 2.73 \\
\hline Senior high school & 57 & 11.97 \\
\hline College & 294 & 61.77 \\
\hline Master or higher & 112 & 23.53 \\
\hline \multicolumn{3}{|l|}{ Marital status } \\
\hline Unmarried & 177 & 37.19 \\
\hline Married & 279 & 58.61 \\
\hline Divorced, widows or widowers & 20 & 4.20 \\
\hline \multicolumn{3}{|l|}{ Monthly income, yuan } \\
\hline$<2000$ & 31 & 6.51 \\
\hline $2000-$ & 153 & 32.14 \\
\hline 5000-9999 & 181 & 38.03 \\
\hline$\geq 10,000$ & 111 & 23.32 \\
\hline \multicolumn{3}{|l|}{ Place of habitual residence } \\
\hline Urban & 442 & 92.86 \\
\hline Rural & 34 & 7.14 \\
\hline \multicolumn{3}{|l|}{ Place of residence during the spring festival } \\
\hline Urban & 413 & 86.76 \\
\hline Rural & 63 & 13.24 \\
\hline
\end{tabular}

sources. Other most commonly used channels were authoritative websites (49.37\%), WeChat subscriptions (42.86\%), Sina Weibo (40.76\%), short messages sent by the government (32.98\%), medical app Ding Xiang Yuan (24.79\%) and free media websites (23.95\%). 15.97\% of respondents used community information platforms (bulletin board services, posters and broadcasting), and $11.55 \%$ used community workers as the main information source.

\section{Public Risk Perceptions Towards COVID-19}

Residents perceived the highest risk towards the infectivity of COVID-19, followed by pathogenicity, lethality and selfrated infection possibility. $96.22 \%$ of respondents thought that the infectivity of COVID-19 was very high or high. $83.41 \%$ thought the pathogenicity of COVID-19 was very high or high. $34.45 \%$ perceived COVID-19 to be very highly deadly or deadly, and $45.17 \%$ perceived it to be moderate. 39 $(8.19 \%)$ respondents rated their infection chance to be very 
likely or likely. Among them, 38 lived in the urban area of the city (Table 2).

\section{Factors Affecting Public Risk Perceptions Towards COVID-19}

To analyze the difference of risk perceptions towards COVID-19 across demographic characteristics and information sources. The score of four and five was considered as high risk, and the score of 1-3 was considered as low risk. Risk perceptions towards the infectivity, pathogenicity, lethality and self-rated infection possibility differed by demographic characteristics and commonly used information channels (Table 3).

\section{Logistic Regression Analysis of Public Risk Perception}

Respondents' demographic characteristics and commonly used information channels were independent variables in the binary logistic modeling analysis for public risk perceptions. Females $(\mathrm{OR}=4.234$, [95\% CI 1.511-11.861]), residents with monthly income $\geq 2000$ yuan (2000-4999 yuan: $\mathrm{OR}=5.052$, [95\% CI 1.164-21.934]; 5000-9999 yuan: $\mathrm{OR}=4.301$, [95\% CI 1.080-17.127]; $\geq 10,000$ yuan: $\mathrm{OR}=23.459$, [95\% CI 2.312-238.080]) and people living with children ( $\mathrm{OR}=5.080$, [95\% CI 1.111-23.273]), perceived a higher risk towards the infectivity of COVID-19, while residents using WeChat contacts as main information source perceived lower $(\mathrm{OR}=0.196$, [95\% CI 0.054-0.072]). People who used television $(\mathrm{OR}=2.563$, [95\% CI 1.504-4.368]) and community workers $(\mathrm{OR}=4.064$, [95\% CI 1.205-13.704]) as main information source, perceived a higher risk of the pathogenicity of COVID-19. The perceived risk of pathogenicity increased by $4.9 \%$ for every one-year increase of age. The married (OR $=1.811$, [95\% CI 1.193-2.748]), the divorced, widows or widowers $(\mathrm{OR}=3.038$, [95\% CI 1.179-7.830]) and people who used free media websites $(\mathrm{OR}=1.756$, [95\% CI 1.130-2.729]) perceived a higher risk of the lethality of COVID-19. People who used community information platforms $(\mathrm{OR}=2.235$, [95\% CI 1.052-4.747]) as main information source and who lived with families with chronic diseases $(\mathrm{OR}=2.423$,
[95\% CI 1.222-4.804]) estimated greater likelihood of being infected COVID-19 (Table 4).

\section{Discussion}

This survey was conducted on February 13rd to 14th, when the number of newly diagnosed cases and suspected cases was declining and the number of cured cases was increasing in China. Work from home policy was gradually replaced by the routine condition. Moreover, a large number of migration population would go in and out of Chongqing. The city was faced with risk of possible rebound of epidemic after work resumption. In our study, residents in Chongqing had a high level of risk perception towards the infectivity and pathogenicity of COVID-19, and relatively lower risk of the lethality and self-rated infection possibility. The risk was perceived based on the information from all information channels, reflecting people's judgement of the characteristics and severity of COVID-19 epidemic. It demonstrated that residents in Chongqing had a rational understanding and attitude towards the disease.

Demographics impact on public risk perceptions during the COVID-19 epidemic. In the study, females, highincome groups, the elderly, married residents or residents with marriage history, and people living with children or families with chronic diseases perceived a higher risk. People are all generally susceptible to COVID-19. Females, the elderly, residents with chronic diseases, and children are the vulnerable groups and need special attention in healthcare management. The elderly and patients with comorbidities are more prone to be infected and progressed to serious complications [3]. A small number of cases showed that the clinical characteristics of pregnant women confirmed COVID-19 infection were similar to non-pregnant adults, however, pregnant women could also be more susceptible to COVID-19 infection versus the general population [12]. The National Health Commission proposed strengthening health counselling, screening and follow-ups for pregnant women, to ensure maternal and fetal safety. Epidemiological data from many countries reflected lower susceptibility among children compared with adults. Most pediatric patients had mild or moderate type of COVID-19, but large
Table 2 Personal risk perception towards COVID-19 $(N=476)$

\begin{tabular}{|c|c|c|c|c|c|c|}
\hline & \multicolumn{5}{|c|}{ Score $(n, \%)$} & \multirow[t]{2}{*}{$-x \pm s$} \\
\hline & 1 & 2 & 3 & 4 & 5 & \\
\hline Infectivity & 0,0 & $2,0.42$ & $16,3.36$ & $139,29.20$ & $319,67.02$ & $4.63 \pm 0.57$ \\
\hline Pathogenicity & 0,0 & $10,2.10$ & $69,14.95$ & $217,45.59$ & $180,37.82$ & $4.19 \pm 0.76$ \\
\hline Lethality & $5,1.05$ & $92,19.33$ & $215,45.17$ & $116,24.37$ & $48,10.08$ & $3.23 \pm 0.91$ \\
\hline $\begin{array}{l}\text { Self-rated infec- } \\
\text { tion possibility }\end{array}$ & $106,22.27$ & $175,36.77$ & $156,32.77$ & $27,5.67$ & $12,2.52$ & $2.29 \pm 0.96$ \\
\hline
\end{tabular}


Table 3 Categorical difference of risk perceptions towards COVID-19 $(N=476)$

\begin{tabular}{|c|c|c|c|c|}
\hline & \multicolumn{2}{|c|}{ Risk perception $(n, \%)$} & \multirow[t]{2}{*}{$\chi^{2}$} & \multirow[t]{2}{*}{$P$} \\
\hline & High & Low & & \\
\hline \multicolumn{5}{|l|}{ Infectivity } \\
\hline Gender & & & 6.575 & 0.010 \\
\hline Male & $152,31.93$ & $6,1.26$ & & \\
\hline Female & $306,64.29$ & $12,2.52$ & & \\
\hline Monthly income, yuan & & & 8.034 & $0.008^{\mathrm{a}}$ \\
\hline$<2000$ & $27,5.67$ & $4,0.84$ & & \\
\hline$\geq 10,000$ & $110,23.11$ & $1,0.21$ & & \\
\hline Use of WeChat contacts & & & 5.318 & 0.021 \\
\hline No & $202,42.44$ & $3,0.63$ & & \\
\hline Yes & $256,53.78$ & $15,3.15$ & & \\
\hline Use of authoritative websites & & & 5.516 & 0.019 \\
\hline No & $227,47.69$ & $14,2.94$ & & \\
\hline Yes & $231,48.53$ & $4,0.84$ & & \\
\hline Living with children & & & 4.049 & 0.044 \\
\hline No & $303,63.66$ & $16,3.36$ & & \\
\hline Yes & $155,32.56$ & $2,0.42$ & & \\
\hline \multicolumn{5}{|l|}{ Pathogenicity } \\
\hline Age, year & & & 10.862 & $0.001^{\mathrm{a}}$ \\
\hline$<30$ & $39,16.26$ & $121,25.42$ & & \\
\hline $50 \sim 59$ & $3,0.63$ & $58,12.18$ & & \\
\hline Marital status & & & 15.025 & $<0.001^{\mathrm{a}}$ \\
\hline Unmarried & $132,27.73$ & $45,9.45$ & & \\
\hline Married & $247,51.89$ & $32,6.72$ & & \\
\hline Use of WeChat subscriptions & & & 4.109 & 0.043 \\
\hline No & $235,49.37$ & $37,7.77$ & & \\
\hline Yes & $162,34.03$ & $42,8.83$ & & \\
\hline Use of television & & & 16.530 & $<0.001$ \\
\hline No & $177,37.18$ & $55,11.55$ & & \\
\hline Yes & $220,46.22$ & $24,5.05$ & & \\
\hline Use of community workers & & & 5.577 & 0.018 \\
\hline No & $345,72.48$ & $76,15.97$ & & \\
\hline Yes & $52,10.92$ & $3,0.63$ & & \\
\hline \multicolumn{5}{|l|}{ Lethality } \\
\hline Educational level & & & 9.120 & $0.003^{\mathrm{a}}$ \\
\hline Senior high school & $28,5.88$ & $29,6.09$ & & \\
\hline Master or higher & $29,6.09$ & $83,17.44$ & & \\
\hline Marital status & & & 6.857 & $0.011^{\mathrm{a}}$ \\
\hline Unmarried & $47,9.87$ & $130,27.31$ & & \\
\hline Married & $107,22.48$ & $172,36.13$ & & \\
\hline Use of free media websites & & & 4.828 & 0.028 \\
\hline No & $115,24.16$ & $247,51.89$ & & \\
\hline Yes & $49,10.29$ & $65,13.66$ & & \\
\hline Use of television & & & 4.450 & 0.035 \\
\hline No & $69,14.50$ & $163,34.24$ & & \\
\hline Yes & $95,19.96$ & $149,31.30$ & & \\
\hline \multicolumn{5}{|l|}{ Self-rated infection possibility } \\
\hline Place of residence during the spring festival & & & 5.871 & 0.045 \\
\hline Urban & $38,8.00$ & $375,7.78$ & & \\
\hline Rural & $1,0.20$ & $2,13.02$ & & \\
\hline
\end{tabular}


Table 3 (continued)

\begin{tabular}{llccc}
\hline & \multicolumn{2}{l}{ Risk perception $(n, \%)$} & \multirow{2}{*}{$\chi^{2}$} & \multicolumn{1}{c}{$P$} \\
\cline { 2 - 3 } & \multicolumn{1}{l}{ High } & Low & & \\
\hline Use of community information platforms & & & 4.742 & 0.029 \\
No & $28,5.88$ & $372,78.15$ & & \\
yes & $11,2.31$ & $65,13.66$ & & \multirow{2}{*}{0.009} \\
Living with families with chronic diseases & & & 6.882 & \\
No & $14,2.94$ & $252,52.94$ & & \\
Yes & $25,5.25$ & $185,38.87$ & & \\
\hline
\end{tabular}

apost hoc comparison

Table 4 Logistic regression modeling of risk perceptions towards COVID-19 $(N=476)$

\begin{tabular}{|c|c|c|c|c|c|c|c|c|}
\hline & & \multirow[t]{2}{*}{$\beta$} & \multirow[t]{2}{*}{ SE } & \multirow[t]{2}{*}{ Wald } & \multirow[t]{2}{*}{$P$} & \multirow[t]{2}{*}{$\operatorname{Exp}(\beta)$} & \multicolumn{2}{|l|}{$95 \% \mathrm{CI}$} \\
\hline & & & & & & & Lower & Upper \\
\hline \multirow[t]{7}{*}{1} & Infectivity $^{\mathrm{a}}$ & & & & & & & \\
\hline & Gender & 1.443 & 0.526 & 7.539 & 0.006 & 4.234 & 1.511 & 11.861 \\
\hline & Monthly income (2000-4999 yuan) & 1.620 & 0.749 & 4.676 & 0.031 & 5.052 & 1.164 & 21.934 \\
\hline & Monthly income (5000-9999 yuan) & 1.459 & 0.705 & 4.281 & 0.039 & 4.301 & 1.080 & 17.127 \\
\hline & Monthly income ( $\geq 10,000$ yuan) & 3.155 & 1.182 & 7.122 & 0.008 & 23.459 & 2.312 & 238.080 \\
\hline & Use of WeChat contacts & 1.628 & 0.663 & 6.029 & 0.014 & 0.196 & 0.054 & 0.072 \\
\hline & Living with children & 1.626 & 0.776 & 4.392 & 0.036 & 5.085 & 1.111 & 23.273 \\
\hline \multirow[t]{4}{*}{2} & Pathogenicity ${ }^{\mathrm{b}}$ & & & & & & & \\
\hline & Age, year & 0.048 & 0.014 & 12.631 & $<0.001$ & 1.049 & 1.022 & 1.077 \\
\hline & Use of television & 0.941 & 0.272 & 11.975 & 0.001 & 2.563 & 1.504 & 4.368 \\
\hline & Use of community workers & 1.402 & 0.620 & 5.112 & 0.024 & 4.064 & 1.205 & 13.704 \\
\hline \multirow[t]{4}{*}{3} & Lethality $^{c}$ & & & & & & & \\
\hline & Marital status (married) & 0.594 & 0.213 & 7.773 & 0.005 & 1.811 & 1.193 & 2.748 \\
\hline & Marital status (divorced, widows or widowers & 1.111 & 0.483 & 5.293 & 0.021 & 3.038 & 1.179 & 7.830 \\
\hline & Use of free media websites & 0.563 & 0.225 & 6.276 & 0.012 & 1.756 & 1.130 & 2.729 \\
\hline \multirow[t]{3}{*}{4} & Self-rated infection possibility ${ }^{\mathrm{d}}$ & & & & & & & \\
\hline & Use of community information platforms & 0.804 & 0.384 & 4.377 & 0.036 & 2.235 & 1.052 & 4.747 \\
\hline & Living with families with chronic diseases & 0.885 & 0.349 & 6.426 & 0.011 & 2.423 & 1.222 & 4.804 \\
\hline
\end{tabular}

${ }^{\mathrm{a}} \chi^{2}: 28.541, P<0.001$; male, monthly income $<2000$ yuan, not using WeChat contacts as main source, or not living with children as reference group

${ }^{\mathrm{b}} \chi^{2}: 39.592, P<0.001$; not using television or community workers as main source as reference group

${ }^{c} \chi^{2}: 15.200, P=0.002$; unmarried, not using free media websites as main source as reference group

${ }^{\mathrm{d}} \chi^{2}: 10.829, P=0.004$; not using community information platforms, or not living with families with chronic diseases as reference group

proportion of asymptomatic children may increase the difficulty of epidemic surveillance $[2,13]$. Moreover, children in Europe were stricken by a novel severe Kawasaki-like disease related to COVID-19 [14]. Authorities don't advise parents to put on mask for children younger than 1-year-old for the risk of suffocation, and active prevention measures like staying at home are more encouraged.

For one thing, high risk perceptions may enhance the public's active response to the epidemic. In Zika prevention, pregnant women's personal risk perception was increased after exposure to intervention provided by CDC [15]. Their degree of concerning about Zika, self-rated chance of being infected and confidence in ability to protect self and baby was significantly elevated, and self-protection behaviors like mosquito repellent use, long-pant wearing became more frequent. During the first wave of the 2009 H1N1 pandemic in Hong Kong, residents' lower perceived severity of H1N1 was associated with less use of hygiene measures [16]. Therefore, the higher risk perceived by vulnerable groups may promote their self-protection behaviors, which is beneficial for infection control. For people who perceived low risk towards COVID-19, they may underestimate the threat 
from the highly contagious disease and were less likely to adopt self-protective behaviors. This group of people are a prime target for public health education.

For another, perceptions of risk could amplify the social, political, and economic impact of the epidemic well beyond its direct consequences [10]. People who perceived high risk towards COVID-19 may suffer from strong negative emotions, resulting stress, panic and conformity to others' behaviors [10]. Psychological and psychiatric services should be implemented to deal with the COVID-19 crisis.

To ensure effective and efficient disclosure of epidemic information, a daily press release system has been established by the National Health Commission. The local government of Chongqing also released daily epidemic report. Numbers of newly diagnosed cases, suspected cases, dead cases and close contacts, are announced by channels of television, websites, WeChat subscriptions and apps like Ding Xiang Yuan, et al. Because of the lockdown of communities, these media became the main information sources for citizens to obtain information about the trajectory of COVID-19 epidemic. At the initial stage of COVID-19 transmission, the uncertainty of epidemic control effect, no vaccines and specific medicine, all gave rise to public's fear for the emerging disease. In our study, information channels including television, free media websites, community workers and community information platforms increased residents' risk perceptions. Interestingly, people who used WeChat friends and groups as main information source perceived a lower risk. WeChat provided information exchange with personal contacts like families, friends and colleagues versus data disclosed by authoritative channels. Social contacts during the epidemic seemed to decreased residents' judgement about the severity of COVID- 19.

COVID-19 is a highly contagious infectious disease. Public awareness of dealing with COVID-19 is important in limiting the spread of infection [17]. Public risk perceptions may change with the trajectory of the disease [16], and social networks amplify the spread of behaviors that are both beneficial and harmful during an epidemic [18]. In dealing with major public health emergencies, when individuals exchange information and opinions with institutions and organizations, the effective use of communication channels to rationally distribute information should be advocated, to meet the psychological needs of the population.

\section{Limitations of the Study}

Because of community lockdown and regulations on disease control and prevention, this study did not perform on-site investigation on February. The online questionnaire survey accessed less sample of males, less-educated population and people living in rural areas of Chongqing. In the future we should focus more on how these population perceive and respond to the risk of emerging infectious diseases.

\section{Conclusion}

In conclusion, residents perceived a high risk towards COVID-19 epidemic at the time close to the work resumption on February in Chongqing, which demonstrated residents' rational understanding of the epidemic. Perceptions of risk towards COVID-19 were impacted by residents' demographic characteristics and main media sources used by them. In the management of public health emergencies, the level of risk perceptions should be monitored. It may be helpful in guiding how individuals and communities should prepare for and respond to the COVID-19 epidemic, and helpful in the information disclosure and policy formulation in a timely, active and precise manner.

Acknowledgements The authors wish to thank all residents for participation in the study.

Author Contributions All authors have made substantial contributions to (1) the conception and design of the study, the acquisition of data, analysis and interpretation of data, (2) the drafting of the article and by revising it critically for important intellectual content, (3) final approval of the version of the manuscript to be submitted.

Funding This study was funded by the COVID-19 prevention and control emergency research project of School of Public Health and Management, Chongqing Medical University (Grant Number 2020YJ01).

\section{Compliance with Ethical Standards}

Conflict of interest The authors declare that they have no conflict of interest.

\section{References}

1. Gao, G. F. (2018). From "A"IV to “Z”IKV: Attacks from emerging and re-emerging pathogens. Cell, 172(6), 1157-1159. https://doi. org/10.1016/j.cell.2018.02.025.

2. Zhu, N., Zhang, D., Wang, W., et al. (2020). A novel coronavirus from patients with pneumonia in China, 2019. New England Journal of Medicine, 382(8), 727-733. https://doi.org/10.1056/NEJMo a2001017.

3. Li, Q., Guan, X., Wu, P., et al. (2020). Early transmission dynamics in wuhan, china, of novel coronavirus-infected pneumonia. New England Journal of Medicine, 382(13), 1199-1207. https:// doi.org/10.1056/NEJMoa2001316.

4. Huang, C., Wang, Y., Li, X., et al. (2020). Clinical features of patients infected with 2019 novel coronavirus in Wuhan China. The Lancet, 395(10223), 497-506. https://doi.org/10.1016/S0140 -6736(20)30183-5.

5. Wang, C., Horby, P. W., Hayden, F. G., \& Gao, G. F. (2020). A novel coronavirus outbreak of global health concern. The Lancet, 395(10223), 470-473. https://doi.org/10.1016/S0140 $-6736(20) 30185-9$. 
6. Five imported cases of novelvirus infected peumonia were confirmed in Chongqing (2020). Retrieved June 1, 2020, from https ://wsjkw.cq.gov.cn/ztzl_242/qlzhxxgzbdfyyqfkgz/yqtb/202001/ t20200121_6478396.html.

7. 2019 Health Statistics of Chongqing (2019). Retrieved June 1, 2020, from https://wsjkw.cq.gov.cn/zwgk_242/fdzdgknr/tjxx/sjzl/.

8. Health committee and civil affairs bureau mobilized urban and rural communities to carry out disease prevention work (2020). Retrieved June 1, 2020, from https://wsjkw.cq.gov.cn/ztzl_242/ qlzhxxgzbdfyyqfkgz/gzdtqlzhyqfk/202002/t20200201_64796 66.html.

9. Slovic, P. (1987). Perception of risk. Science, 236(4799), 280-285.

10. Burns, W. J., \& Slovic, P. (2012). Risk perception and behaviors: anticipating and responding to crises. Risk Analysis, 32(4), 579-582. https://doi.org/10.1111/j.1539-6924.2012.01791.x.

11. Chinese Center for Disease Control and Prevention. (2020). The epidemological characteristics of an outbreak of 2019 novel coronavirus diease (COVID-19) in China. Chinese Journal of Epidemiology, 41(2), 145-151.

12. Qiao, J. (2020). What are the risks of COVID-19 infection in pregnant women? The Lancet, 395(10226), 760-762. https://doi. org/10.1016/S0140-6736(20)30365-2.

13. Parri N, Lenge M, Buonsenso D. (2020). Coronavirus infection in pediatric emergency departments research G. Children with Covid-19 in pediatric emergency departments in Italy. New England Journal of Medicine.

14. Viner, R. M., \& Whittaker, E. (2020). Kawasaki-like disease: emerging complication during the COVID-19 pandemic. The Lancet. https://doi.org/10.1016/S0140-6736(20)31129-6.
15. Earle-Richardson, G., Prue, C., Turay, K., \& Thomas, D. (2018). Influences of community interventions on zika prevention behaviors of pregnant women, puerto rico, July 2016-June 2017(1). Emerging Infectious Diseases, 24(12), 2251-2261. https://doi. org/10.3201/eid2412.181056.

16. Cowling, B. J., Ng, D. M., Ip, D. K., et al. (2010). Community psychological and behavioral responses through the first wave of the 2009 influenza $\mathrm{A}(\mathrm{H} 1 \mathrm{~N} 1)$ pandemic in Hong Kong. The Journal of Infectious Disease, 202(6), 867-876. https://doi. org/10.1086/655811.

17. Abdelhafiz, A. S., Mohammed, Z., Ibrahim, M. E., et al. (2020). Knowledge, Perceptions, and Attitude of Egyptians Towards the Novel Coronavirus Disease (COVID-19). Journal of Community Health. https://doi.org/10.1007/s10900-020-00827-7.

18. Bavel, J. J. V., Baicker, K., Boggio, P. S., et al. (2020). Using social and behavioural science to support COVID-19 pandemic response. Nature Human Behaviour, 4(5), 460-471. https://doi. org/10.1038/s41562-020-0884-z.

Publisher's Note Springer Nature remains neutral with regard to jurisdictional claims in published maps and institutional affiliations. 